\title{
FEASIBILITY STUDY FOR A NEW STRUCTURAL SYSTEM TO RESIST THE COLLAPSE OF REINFORCED CONCRETE FRAME STRUCTURES IN EARTHQUAKES
}

\author{
ZHANG FENGBO ${ }^{1,2} \&$ LIN FENG $^{1}$ \\ ${ }^{1}$ Department of Structural Engineering, Tongji University, China \\ ${ }^{2}$ Department of Construction Engineering, Universitat Politècnica de Catalunya, Spain
}

\begin{abstract}
Having collapse-resistant building structures is significant when buildings are constructed in earthquake-prone areas. For reinforced concrete (RC) moment-resisting frame structures, structural collapse generally originates from the failure of a column on the ground floor. In this paper, we propose a new girder-cable composite system that could act as a passive protection system, to improve collapse resistance of structures with a RC frame. The operating principle is presented; also, we demonstrated the application feasibility of the system using a double-span beam test. The cables were made up of high-strength, pre-stressed reinforced steel bars and they were positioned directly underneath all girders on the ground floor of the structure. Both ends of each cable were fastened to adjacent beam-column joints, which made it possible to provide large horizontal tensile forces. Originally, all cables were loose and did not come into operation before the failure of a column on the ground floor; however, the cables did start working at a threshold value with a large elongation. This elongation value was triggered due to the failure of a column on the ground floor accompanying a large deflection of the adjacent double-span girder. As a result, the load-bearing capacity that was originally provided by double-span girders was significantly improved when the girder-cable composite system was used; thus, the potential collapse of structures in a vertical direction could be prevented. The proposed system is based on a clear principle and has the advantage of providing a dramatic improvement effect on the load-bearing capacities of RC frame structures.
\end{abstract}

Keywords: building construction, building frame, cable, collapse resistance, column failure, earthquakes, load-bearing capacity, reinforced concrete, structural system.

\section{INTRODUCTION}

Building structures may be destroyed when undergoing strong earthquakes. Their collapse resistance is of significance for buildings located in earthquake-prone areas. For a reinforced concrete (RC), moment-resisting frame structure, a large-scale collapse is generally initiated from the failure of an important structural member, which is generally a column on the ground floor, and then the failure region spreads out. This is because:

1. The safety margins of the columns are different from each other;

2. Vertical loads (particularly live loads) applied on the columns in the event of an earthquake usually varies from the design scenario, which causes the generated horizontal forces to differ from the designed ones;

3. The construction quality of the columns present are different from each other; and

4. The seismic action is not the same as had been assumed, due to the randomness of earthquakes.

After the failure of the first column, the building destruction develops in two modes [1]: the first one is a collapse in the vertical direction, mainly due to the collapse of the structures above the failed column. The second is a collapse in the horizontal direction, in the case where the adjacent columns then fail, one after another. 
Targeted consideration should be given for the different collapse modes of a RC frame structure when under an earthquake, to resist collapse. For the collapse in a vertical direction, in this study we propose a new structural system. The idea to do so was inspired by the work done by Tan and Astaneh-Asl [2]: they used cables located underneath steel girders to increase the collapse resistance of steel structures. The catenary action of the cables in their test created significant improvements in the collapse resistance of steel structures. In this paper, cables were also used and positioned underneath RC girders, to resist the vertical collapse of a RC framed structure. The contribution of the cables was not activated in the service condition; however, the cables came into operation at the stages of compressive arch action and catenary action of the girders. The system components were present and an improvement effect was demonstrated by means of an example.

\section{OPERATING PRINCIPLE OF THE SYSTEM}

\subsection{Response of the double-span beam after the failure of a column}

Fig. 1 shows the deformation of a RC frame structure after the failure of a middle column on the ground floor, accompanied with a large vertical displacement of the column top. The related failure region can be further simplified to a double-span beam [3]. If the premature shear failure of the double-span beam is prevented, the double-span beam will behave following three main stages, i.e., a bending stage (from points A to B), a compressive arch action stage (from points $B$ to $C$ ), and a catenary action stage (from points $C$ to $D$ ), as presented in Fig. 2. The traditional design only takes into account the limited bending bearing capacity in the bending stage; however, in a collapse-resistant design, the capacity provided by the catenary action should also be considered for economic reasons. In this stage, the reinforcing steel bars on the bottom and top of the beam are activated to generate the catenary action. Finally, if the reinforcements are ruptured one after another, the double-span beam completely fails.

Improvement of the catenary action can be achieved by increasing the amount of the reinforcements in beams; however, this results in a limited effect when a common design strategy is used. The reason lies in two aspects: on the one hand, the amount of the reinforcements is limited by the maximum reinforcement ratio; and on the other hand, the ultimate strength of reinforcing steel bars (e.g., HRB400 and HRB500 that are widely used in China) are about $600 \mathrm{MPa}$. These strengths are comparatively small with respect to pre-stressed steel bars and steel stands, with their ultimate strengths being about 1000-2000 MPa.

\subsection{Response of girder-cable composite structure after the failure of a column}

The collapse resistance of the two-span girder can be significantly increased by using a girder-cable composite structure. The idea is to generate a cable system that contributes to help resist the collapse of the $\mathrm{RC}$ frame structure in the event of a column failure. The configuration of the girder-cable composite structure is illustrated in Fig. 3.

A cable device is positioned underneath each girder (Fig. 3(a)) and consists of two cable parts and a cable sleeve. The cable parts can be made using pre-stressed steel bars or other bars with high strength.

The cable sleeve is used to connect the two cable parts. One end of the cable is anchored on the top of the column in the beam-column joints. The other end is inserted into the cable sleeve where it can slide slightly without friction (Fig. 3(b)). The sliding distance is carefully 


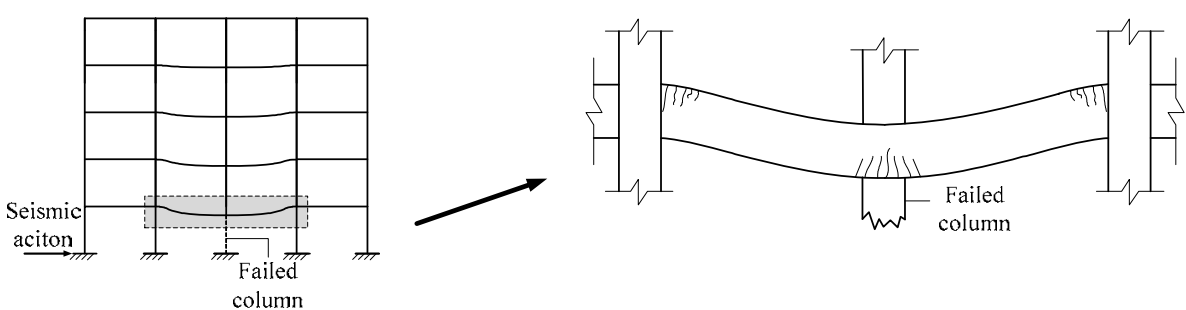

Figure 1: The deformation of a structure in the event of a column failure.
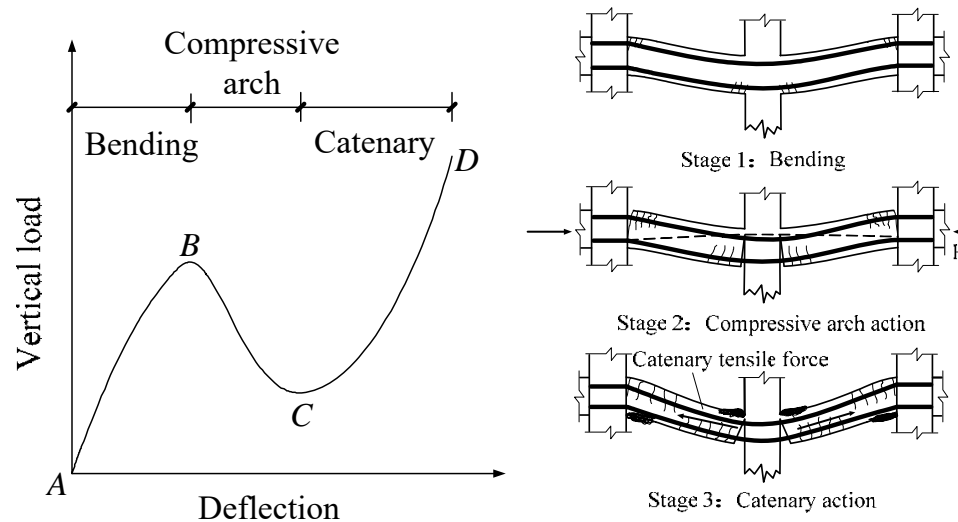

Stage 1: Bending

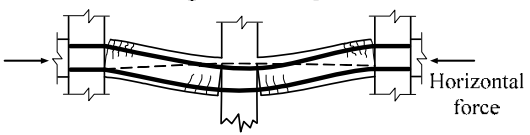

Stage 2: Compressive arch action

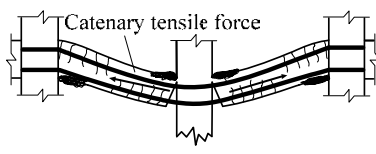

Stage 3: Catenary action

Figure 2: Loading stages of the two-span beam.

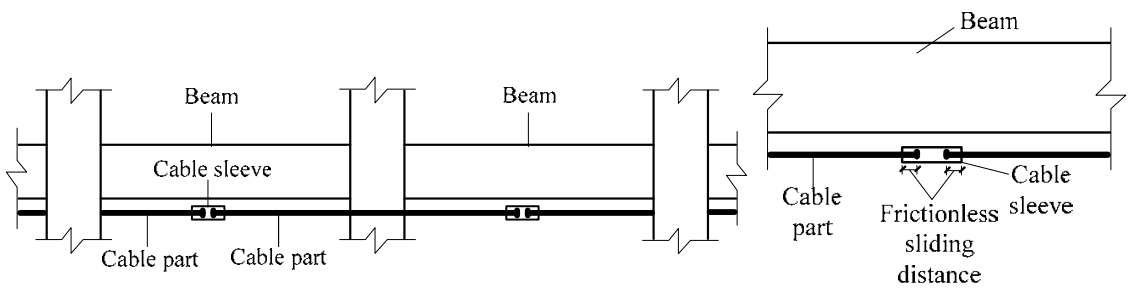

(a) The system components and device position;

(b) Initial state before the failure of a column;

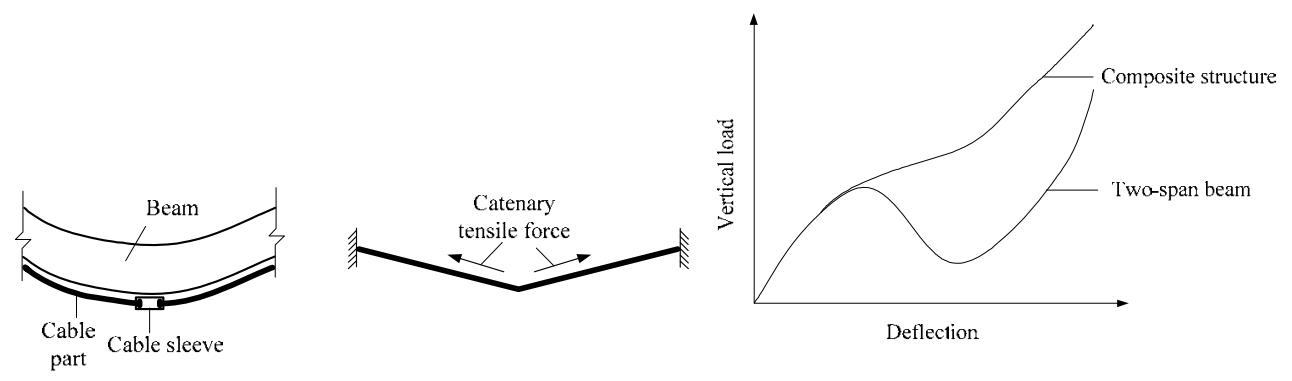

(c) Catenary action after the failure of a column; (d) The resistance provided by the composite structure.

Figure 3: Configuration of the girder-cable composite structure. 
pre-determined by calculation. This device is loose before the failure of the middle column. In the event of the failure of the column, the vertical displacement in that place will dramatically increase, which results in the extension of the device. When the double-span beam reaches its ultimate bending capacity, the device becomes tightened and starts to work with the double-span beam (Fig. 3(c)). The device keeps resisting collapse during the compressive arch action stage and the catenary action stage (Fig. 3(d)). Apparently, the amount of the outer pre-stressed steel bars is not limited by the reinforcement ratios; thus, collapse resistance can be extremely increased, by the proper use of our girder-cable composite structure.

Attention should be given when using the proposed composite structure. The device does not normally do any work in the service condition; but after a column fails in an earthquake; the device starts to work and to provide resistance in the stages of compressive arch action and catenary action. These two requirements can be satisfied by calculating a sliding distance for the cable device.

The new system cannot be applied to resist horizontal collapse of the RC frame structures when subjected to earthquakes. It is also assumed that the catenary action can be triggered and put into use in the case of the RC frame structures vertically collapsing [4]-[5]. This system cannot be applied in the case of a failure of a corner column, because no catenary action occurs in that case.

\section{EXAMPLE}

The feasibility of the girder-cable composite system is presented in this section by means of a double-span beam test in the literature [6].

\subsection{Two-span beam test [6]}

Fig. 4 illustrates the test setup of a 1:4 scaled two-span beam specimen, B2, with its failure mode featured with catenary action. A short column in the middle of the span was used to simulate the failed column. Two side columns on each specimen end represented the adjacent columns. The cross-sectional area of the side columns was larger than that of the middle column, to provide higher constraints compared to other elements. The side columns were connected to the reaction wall by bolts through pre-formed holes, which provided both horizontal and bending constraints. The bolts always behaved elastically during the test; thus, the horizontal force and bending moment at the specimen ends could be obtained by measuring the strain of the bolts. Concentrated loads were applied on the top of the middle column, using displacement control. The dimensions and reinforcements are listed in Table 1. Fine aggregate concrete with a compressive strength of $f_{\mathrm{c}}=25.8 \mathrm{MPa}$ was used. The reinforcing steel bar, D6, had a yield strength of $569 \mathrm{MPa}$ and an ultimate strength of 713.9 $\mathrm{MPa}$. The reinforcing steel bar D8 had a yield strength of $537 \mathrm{MPa}$ and an ultimate strength of $670.1 \mathrm{MPa}$. The thickness of the concrete cover was $20 \mathrm{~mm}$.

Fig. 5(a) presents the relationship between the load $P$ and the mid-span displacement, $\Delta$. The whole process consisted of three stages: bending action, compressive arch action and catenary action [6]. The first and second stages were distinguished by their axial force, $N=0.1 f_{\mathrm{c}} b h$; because no effect was found on the bending capacity if the axial force was less than this value [7]. In the initial loading stage, $P$ increased linearly with. $\Delta$ Yield load $P_{\mathrm{y}}$ was reached when the tensile reinforcements on the specimen bottom yielded. When one keeps increasing the loads, the neutral axes close to the beam end and the middle column moved down and up, respectively. Meanwhile, the horizontal deformation was restrained and the horizontal force was then increasing. As a result, the compressive arch 
action of the specimen activated. With the increment in $\Delta$, the compressive concrete at the end and around the middle column became crushed. The axial force turned from compression to tension, which meant the catenary action began. Subsequently, the bottom bars in the specimen ruptured, due to the tensile force, and the test was stopped for the sake of safety. It could be predicted that the top bars would also rupture if the loads had continued to increase.

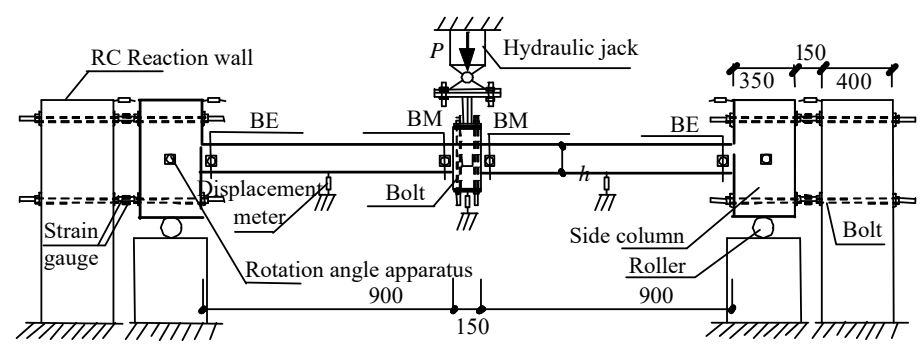

Note: BE represents the cross section of the beam close to the side columns

$\mathrm{BM}$ represents the cross section of the beam close to the middle column

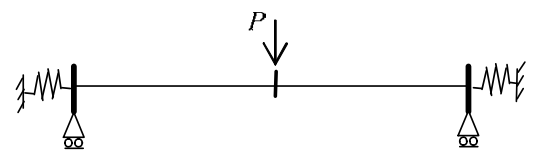

(a) Test setup;

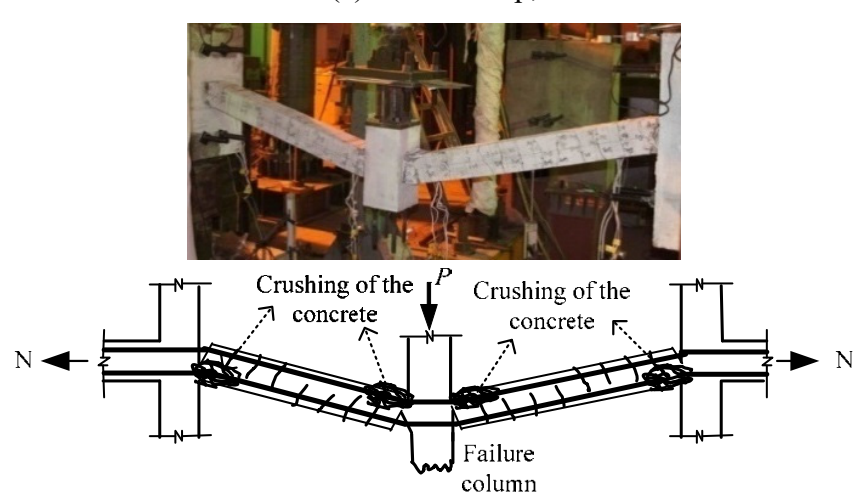

(b) Failure mode.

Figure 4: Test setup and failure mode of specimen B2.

Table 1: Dimensions and reinforcements of specimen B2.

\begin{tabular}{|c|c|c|c|c|}
\hline \multirow[b]{2}{*}{ Component } & \multirow{2}{*}{$\begin{array}{l}\text { Net span of } \\
\text { beam or column } \\
\text { height (mm) }\end{array}$} & \multirow[b]{2}{*}{$\begin{array}{l}\text { Cross-section } \\
b \times h(\mathrm{~mm})\end{array}$} & \multicolumn{2}{|c|}{ Reinforcement ratio } \\
\hline & & & $\begin{array}{l}\text { Mid-span } \\
\text { cross-section }\end{array}$ & End cross-section \\
\hline Beam & 900 & $100 \times 100$ & $\begin{array}{l}\text { Top 2D8, bottom } \\
\text { 2D6, stirrups } \\
\text { D6@65 }\end{array}$ & $\begin{array}{c}\text { Top 2D8, } \\
\text { bottom 2D6, stirrups } \\
\text { D6@65 }\end{array}$ \\
\hline $\begin{array}{l}\text { Middle } \\
\text { column }\end{array}$ & 300 & $150 \times 150$ & \multicolumn{2}{|c|}{$\begin{array}{c}\text { Longitudinal reinforcement 4D8, } \\
\text { stirrups D6@80 }\end{array}$} \\
\hline Side column & 600 & $350 \times 350$ & \multicolumn{2}{|c|}{$\begin{array}{c}\text { Longitudinal reinforcement 6D20, stirrups } \\
\text { D10@80 }\end{array}$} \\
\hline
\end{tabular}


3.2 Improvement of collapse resistance by using a girder-cable composite system

An imaginary example is presented in this subsection, to demonstrate the improvement in collapse resistance that occurs by using a girder-cable composite system. A pre-stressed steel bar of $1 \phi 18$ (PSB785) with a yield strength of $f_{\text {pyk }}=785 \mathrm{MPa}$ and an ultimate strength of $f_{\mathrm{ptk}}=980 \mathrm{MPa}$ was used as the cable, in order to improve the collapse resistance of specimen B2 [8].

The stress-strain relationship could be expressed as:

$$
\sigma= \begin{cases}E_{\mathrm{s}} \varepsilon & \varepsilon \leq \varepsilon_{\mathrm{y}} \\ 785+6275\left(\varepsilon-\varepsilon_{\mathrm{y}}\right) & \varepsilon_{\mathrm{y}} \leq \varepsilon \leq \varepsilon_{\mathrm{u}} .\end{cases}
$$

Here, $\sigma$ denotes stress and $\varepsilon$ is strain. The elastic modulus $E_{\mathrm{S}}$, yielding strain $\varepsilon_{\mathrm{y}}$ and the ultimate strain $\varepsilon_{\mathrm{u}}$ are $2 \times 10^{5} \mathrm{MPa}, 3.9 \times 10^{-3}$ and 0.035 , respectively.

The loads were applied on the top of the middle column and the imaginary cables were hung under the double-span beam, B2. The cables started to tighten when $P$ reached the yield load, $P_{\mathrm{y}}$. At this moment, the frictionless sliding length of the two cable parts in the cable sleeve was $62.4 \mathrm{~mm}$ (i.e., $31.2 \mathrm{~mm}$ for each span). The maximum deflection of the beam in the one span was $4.5 \mathrm{~mm}$, in accordance with Chinese Code [8]. Correspondingly, the frictionless sliding distance of one cable side should be at least $22.5 \mathrm{~mm}$, which is less than $31.2 \mathrm{~mm}$. This means that the cables are indeed loose and do not work under normal service conditions.

When the loads reached the yield load $P_{\mathrm{y}}$, the cables started to tighten and then acted as a catenary. Based on the equilibrium principle and geometric relationships, the relationship between applied loads $P_{\mathrm{s}}$ and deflection $\Delta_{\mathrm{s}}$ of the cables was expressed as:

$$
P_{\mathrm{s}}=2 T_{\mathrm{s}} \frac{\Delta_{\mathrm{s}}}{l_{\mathrm{n}}}
$$

Here, $T_{\mathrm{s}}$ is the tensile force of the cable and $l_{\mathrm{n}}$ is the span length. The ultimate catenary state of the cable was determined by the ultimate strain $\varepsilon_{\mathrm{u}}$ of the cable. For specimen B2, the maximum load was $133 \mathrm{kN}$ and the mid-span vertical displacement was $240 \mathrm{~mm}$, based on calculations.

The improvement in collapse resistance using a girder-cable composite system is clearly shown in Fig. 5(b), in the form of the relationship between the $P$ and $\Delta$ of the two-span beam. The ultimate displacement of $172 \mathrm{~mm}$ that was observed in the test was less than the $240 \mathrm{~mm}$ in the calculation, in accordance with eqn. (2); however, the loads increased from $18.6 \mathrm{kN}$ in the test to $105 \mathrm{kN}$, based on the calculation, which was about $105 / 18.6 \approx 5.6$ times. This demonstrated the huge improvement in collapse resistance by using our girder-cable composite system.

\section{DISCUSSION}

The example provided was based on a scaled specimen, B2, and the concentrated loads applied in the test were also different from the distributed loads in practice; however, the feasible composite structure and the capacity improvement did have general significance. For instance, if $6 \$ 25$ of PSB785 pre-stressed steel bars were used under a beam with reinforcement 4D25 on the beam top, collapse resistance could be improved by 2.5 times.

Different from the static test used in the example, the collapse of a structure is usually a dynamic process. In addition, the influence of slabs and bi-directional frame beams were not 


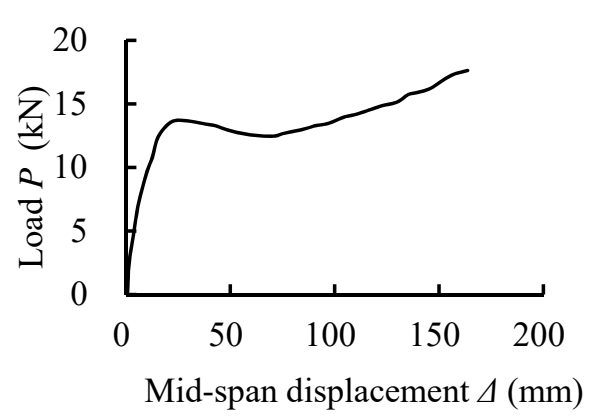

(a) Specimen B2

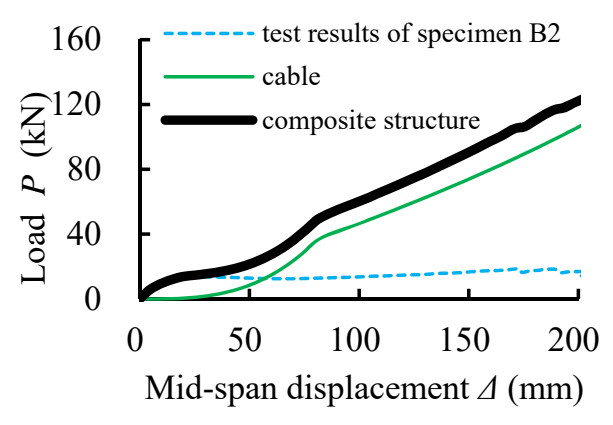

(b) Composite structure

Figure 5: Relationships between loads and mid-span displacement of specimen B2 and composite structure.

considered in the example; however, the proposed system is still valid when taking all these effects into account. In the future, these issues need to be studied.

\section{CONCLUSION}

We proposed a girder-cable composite system to improve the collapse resistance of RC frame structures, when under strong earthquakes. The cables are positioned under the beams and are loose under normal service conditions. The cables come into operation only when a middle column totally fails. The catenary action of the cables then becomes activated, to prevent the collapse of the RC structure in the vertical direction. The feasibility of our system was demonstrated using a test case and significant improvement was verified.

For application of this system in practice, further research is needed, including of the dynamic effect and the spatial effect. It is also important to predict precisely the displacement produced, using non-linear dynamic analysis after the failure of a column.

\section{REFERENCES}

[1] Starossek, U., Typology of progressive collapse. Engineering Structures, 29(9), pp. 2302-2307, 2007.

[2] Tan, S. \& Astaneh-Asl, A. Cable-based retrofit of steel building floors to prevent progressive collapse, University of California at Berkeley, 2003.

[3] Izzuddin, B.A. \& Vlassis, A.G., Progressive Collapse of Multi-Storey Buildings Due to Sudden Column Loss-Part I: Simplified Assessment Framework. Engineering Structures, 30(5), pp. 1308-1318, 2008.

[4] General Services Administration (GSA), Progressive collapse analysis and design guidelines for new federal office buildings and major modernization projects, Washington, D.C., 2003.

[5] China Engineering Construction Standardization Association, Code for anti-collapse design of building structures (CECS392:2014), Beijing: Standards Press of China, 2014, (in Chinese).

[6] Wang, Y., Study on progressive collapse resistance design method of reinforced concrete frame structures subjected to accidental actions, Tongji University, Shanghai, 2014, (in Chinese). 
34 Earthquake Resistant Engineering Structures XI

[7] American Concrete Institute Committee 318, Building Code Requirements for Structural Concrete (ACI318-2010) and Commentary (318R-02), Farmington Hills, MI, Washington D.C., 2008.

[8] Ministry of Housing and Urban-Rural Development of the People's Republic of China, Code for design of concrete structures (GB50010-2010), China Architecture and Building Press: Beijing, 2010, (in Chinese). 